\title{
MJN EFFECT OF SOCIAL MEDIA ADDICTION ON ACADEMIC PERFORMANCE AMONG NURSING STUDENTS
}

\author{
Rosuzeita Fauzi, Nor Izzaidah Saaiddin, Nur Shahira Ibrahim, Siti Solehah Abdullah \\ Centre for Nursing Studies, Faculty of Health Sciences, Universiti Teknologi MARA Selangor, Malaysia \\ *Corresponding Author's Email: rosuzeita@uitm.edu.my
}

\begin{abstract}
Background: In Malaysia, the presence of smartphones and gadgets in any situation leads to addiction in social media. Lack of self-regulation of smartphones usage for some students will turn out to be the factor that affects their academic performance the most. Objective: To determine the effect of social media addiction on academic performance among nursing students. Methods: A descriptive and quantitative cross-sectional study design using self-administered questionnaires was conducted among 141 diploma and degree nursing students in Faculty of Health Sciences, UiTM. In the study, the "Social Media Addiction Scale-Student Form" and the CGPA achievement of the students were used. Results: From this study, it was seen that students had a high level of addictiveness $(\mathrm{M}=86.40, \mathrm{SD}=13.78)$. Majority of the students have high CGPA achievement for each semester. Instagram $44(31.2 \%)$ become the platform that students are more exposed. There is no significance difference between social media addiction and academic performance as determined by Kruskal Wallis test, $p=0.830$. Conclusion: It can be concluded that, social media did not give a negative effect on the students' academic performance. This is because some students' performance still remains the same even though they were addicted with social media platforms. It would be better if more universities were included in future studies to prove the relation between social media addiction and academic performance among different nursing students.
\end{abstract}

Keywords: Effect of Social Media; Addiction; Academic Performance; Nursing Students

\section{INTRODUCTION}

The use of social media in society's lifestyle and culture has been increasingly taking place recently. Stat Counter Global Stats (2019) reports that, the latest statistics updated in March 2019 showed that the most famous social media used in Malaysia is Facebook $(84.33 \%)$. A recent study has approved that in 2016, there is an evolution of social media by the statistic given where in average three million reach Facebook monthly and 500 millions of active users worldwide on Twitter. As indicated in the same research, the highest users of the online social media are among teenagers, college and university students (age 18 to 29) as they are constantly linked to the social network sites (Oueder \& Abousaber, 2018). In Malaysia, the presence of smartphones and gadgets in any situation leads to addiction in social media amongst students. Social media poses both pros and cons of usage that can impact students either positively or negatively. The positive is that it allows students access to sharing and publishing some information at anywhere and anytime (Mukhtar et al., 2018). Excessively use of social media surely has an effect on students' life either positive or negative especially on their academic performance.

Nowadays, social media has become essential part of life especially as a student. In line with that, research findings from Mukhtar et al., (2018) found that between 18 to 29 years of age were among $57 \%$ of the social media users. They spent at least 30 minutes on an average of the time spends by students in social media during the daytime and evening. Previous studies have reported more than half of the of students were ranked at a moderate level of internet addiction (Lamia, Osman \& Farrag, 2018). It also shows that students mostly like to 
stay online 24 hours that define students' addictiveness towards social media. The result of social media usage has both constructive or adverse impact especially on their academic performance. Excessive time spend in social networking sites can divert the concentration and shift focus from the particular task (Siddiqui \& Singh, 2016). On the other hand, it can also lead to failure of the education system where many of the bloggers used social media to posts the wrong information regarding the education. This somehow can cause students to misuse the information related to their subjects. In addition, social media have broadened the negative outcome which can also effects health as lots of time is being wasted on social.

Study conducted by Mukhtar et al., (2018) show that regular daily users of social media are among nursing students (84.9\%). Nursing students does utilize the various platforms for their benefits either for academic or for personal life. However, nursing students may lose their ability to engage themselves for face-to-face communication due to social media addiction (Abbas et al., 2019). More or less, social media has become one of the triggering factors for students to abandon their assignment either with or without intention. In the meantime, for them to gain the information through social media, but the social media posting distracts them and they do not stay focus on the academic purpose. The studies show the negative relation between social media usage and academic performance as students were easily distracted with their smartphones (Giunchiglia et al., 2017). Indeed, the usage of smartphone has become normal with students' life as they can access their social media easily. Lack of self-regulation of smartphones usage for some students will turned out to be the one whose affects their academic performance the most. This eventually will result in a bad achievement. The previous studies have shown there is a correlation regarding social media and academic performance. As the study have proven the existence of social media addiction among nursing students in other countries, there will be possibility of the same among nursing students in Malaysia. Thus, this study aims to determine the effect of social media on the academic performance of nursing students.

\section{METHODOLOGY}

Approval was received from the Research Ethics Committee Universiti Teknologi MARA(REC/579/19) and compiled with the Declaration of Helsinki.

\section{Study Design}

The quantitative cross-sectional design was used in this study. Cross sectional studies were used because it is simple to design and directed at the outcome of the incidence of a problem, attitude or issue of social media addiction among nursing students and their academic achievement.

\section{Study Setting}

The study was conducted at the Centre for Nursing Studies, Faculty of Health Sciences at UiTM Selangor, Puncak Alam campus. Nursing student that pursed study in diploma and degree in this university became the target population.

\section{Sample}

In this study, a purposive sampling was used during the selection of the potential students. Respondent has been selected based on name list and the subject has been confronted and gave informed consent in the class, those who refused were not included. At the beginning of the research, the researcher had access to the total number of students enrolled in the diploma and degree program to identify potential participants. Diploma and degree nursing students who are studying at UiTM Puncak Alam who are willing to participate in this research are part of inclusion criteria. Participants must be able to understand the written English language and must have at least one social media account. Meanwhile, the exclusion criteria are first semester students who do not yet have CGPA and those who do not have a social media account.

\section{Sample Calculation}

Calculation of the sample size of Raosoft has been used and the required sample size $\mathrm{N}=222$. As reported by the Raosoft sample size calculator, the error margin is 5 percent, the confidence interval is 95 percent, the population size is $\mathrm{N}=222$ and the response distributions are 50 percent. The calculation resulted in a sample size of $n=141$.

\section{Instrument}

A self-administered questionnaire was completed by all student nurses who met the selection criteria and agreed to participate in the study. The self-administered questionnaires were used as a tool to determine the relationship between social media addiction and academic performance for nursing students. 
Questionnaire for Section A was adapted from Social Media and Academic Performance of Students (SMAAPOS) by Osharive (2015). This questionnaire was used to measure the demographic data and platform that most exposed by students. Demographic data such as sex, age, semester and level of education was collected. Respondents are also being asked about their Grade Point Average (GPA) and Cumulative Grade Point Average (CGPA). In addition, researchers also asked respondents which social media they are members of and which one they used the most. Section B questionnaire adapted from Social Media Addiction Scale- Student Form (SMAS-SF) by Cengiz (2018) were used to determine the relationship between social media addiction and academic performance. In this part, different states related to the use of social media on the internet has been evaluated using five-point Likert Scale (5-strongly agree, 4-agree, 3-neither agree nor disagree, 2-disagree and 1-strongly disagree). The score was used to identify the scale of social media addiction among students. It consists of 29 items and four subdimensions. 5 items are sub-dimensional to virtual tolerance, 9 items are sub-dimensional to virtual communication, 9 items are sub-dimensional to virtual problem and 6 items are sub-dimensional to virtual information. All the items in the scale are positive. The highest point that can be scored on the scale is 145 , and the lowest is 29 . The higher scores indicate as a social media addict. A pilot study was conducted and distributed among 30 respondents to analyse the reliability of the tools used in the research. The Cronbach's alpha coefficients were 0.80 , which was used in the analysis.

\section{Data Collection}

Data were collected over a period of four months. It is conducted from September 2019 to January 2020. Firstly, after gaining ethical consideration and approval, participants that will be selected using purposive sampling were identified and an appointment was made to meet with the class representative. Next, a brief explanation about the study to the class and a written consent was provided along with the questionnaire to respondent to ensure that the respondents have agreed or declined participation to take part in the study. Participants were given simple and concise explanation about the study. They are given 24 hours duration answering the questionnaires as the participants might be busy to answer the questionnaire right away. Researchers' contact information was mentioned in the form, if there are any questions regarding the questionnaires.

The questionnaire was collected and checked to detect any incomplete answer after 24 hours. The participants were asked to redo any incomplete questionnaire right away to prevent decrease in response rate. While the complete questionnaire was double checked to ensure the questionnaire are answered accordingly. The respondent followed the instructions well and proceed to complete the questionnaire. After the respondents finished answering, then the questionnaire was collected and checked for completeness.

\section{Data Analysis}

IBM SPSS version 25.0 was used to analyse all data collected. This software was used because it is more reliable and provides an accurate result for this study. The descriptive statistics was used to determine the mean, standard deviation, minimum, maximum, frequencies and percentages for the variables. The nonparametric analysis Kruskal Wallis was used since the data was nonparametric and not normally distributed.

\section{Table 1: Standard Methodology}

\begin{tabular}{|l|l|}
\hline Objectives & Data Analysis \\
\hline $\begin{array}{l}\text { To examine the level of student } \\
\text { addictiveness to social media among } \\
\text { nursing students }\end{array}$ & $\begin{array}{l}\text { Mean, standard deviation, } \\
\text { minimum and maximum }\end{array}$ \\
\hline $\begin{array}{l}\text { To determine the platform of social } \\
\text { media that the nursing students are } \\
\text { more exposed }\end{array}$ & Frequency and percentage \\
\hline $\begin{array}{l}\text { To identify the relationship between } \\
\text { social media addiction with academic } \\
\text { performance of nursing students }\end{array}$ & Kruskal Wallis \\
\hline
\end{tabular}

\section{RESULTS}

\section{Demographic Data}

Table 2 shows the complete descriptive analysis of demographic data of this study. For GPA 8 students $(5.7 \%)$ got below 3.0, 75 students $(53.2 \%)$ got between 3.00 to 3.49 and 58 students (41.1\%) got 3.5 and above. For CGPA, 12 students (8.5\%) got below 3.0, 95 students $(67.4 \%)$ got between 3.00 to 3.49 and 34 students $(24.1 \%)$ got 3.5 and above. Based on UiTM 
grading, those who achieved between 2.00 to 2.19 is considered as third class, 2.20 to 2.99 is second lower class, 3.00 to 3.49 is second upper class and 3.50 above considered as first class.

Table 2: Presentation of Demographic Data

\begin{tabular}{|c|c|c|}
\hline Variable & Frequency & $\begin{array}{c}\text { Percent } \\
(\%)\end{array}$ \\
\hline \multicolumn{3}{|l|}{ Sex } \\
\hline Male & 18 & 12.8 \\
\hline Female & 123 & 87.2 \\
\hline \multicolumn{3}{|l|}{ Age } \\
\hline 20 & 58 & 41.1 \\
\hline 21 & 41 & 29.1 \\
\hline 22 & 39 & 27.7 \\
\hline 23 & 3 & 2.1 \\
\hline \multicolumn{3}{|l|}{ Level of Education } \\
\hline Diploma & 27 & 19.1 \\
\hline Degree & 114 & 80.9 \\
\hline \multicolumn{3}{|l|}{ GPA } \\
\hline Third class & 0 & 0 \\
\hline Second lower class & 8 & 5.7 \\
\hline Second upper class & 75 & 53.2 \\
\hline First class & 58 & 41.1 \\
\hline \multicolumn{3}{|l|}{ CGPA } \\
\hline Third class & 0 & 0 \\
\hline Second lower class & 12 & 8.5 \\
\hline Second upper class & 95 & 67.4 \\
\hline First class & 34 & 24.1 \\
\hline \multicolumn{3}{|l|}{ Semester } \\
\hline 3 & 40 & 28.4 \\
\hline 5 & 63 & 44.7 \\
\hline 7 & 38 & 27.0 \\
\hline
\end{tabular}

\section{Level of Addictiveness to Social Media among Nursing Students}

Table 3 shows the mean score are collected in 4 subscales. The mean for the subscale of virtual tolerance was $17.35(\mathrm{SD}=3.60)$, virtual communication 25.23 $(\mathrm{SD}=5.18)$, virtual problem s $23.13(\mathrm{SD}=5.52)$ and virtual information was $20.69(\mathrm{SD}=3.84)$. To sum up, the total score mean is 86.40 .
Table 3: Level of Addictiveness to Social Media among Nursing Students

\begin{tabular}{|l|c|c|c|c|}
\hline Variables & Mean & $\begin{array}{c}\text { Standard } \\
\text { deviation }\end{array}$ & Minimum & Maximum \\
\hline Total & $\mathbf{8 6 . 4 0}$ & $\mathbf{1 3 . 7 8}$ & $\mathbf{4 4}$ & $\mathbf{1 2 9}$ \\
\hline Subscales & \multicolumn{5}{|l}{} \\
\hline Virtual tolerance & 17.35 & 3.60 & 8 & 25 \\
\hline Virtual communication & 25.23 & 5.18 & 9 & 41 \\
\hline Virtual problem & 23.13 & 5.52 & 9 & 41 \\
\hline Virtual information & 20.69 & 3.84 & 6 & 29 \\
\hline
\end{tabular}

The Platform of Social Media that Nursing Students are More Exposed

Table 4 shows that mostly students used Instagram 44 (31.2\%), Twitter 38 (27.0\%), YouTube 26 (18.4\%), followed by Facebook $22(15.6 \%)$ and the least was Snapchat $1(0.7 \%)$.

Table 4: Social Media Platform Most Exposed by Nursing Students

\begin{tabular}{|l|c|c|}
\hline Variable & Frequency & Percentage \\
\hline Facebook & 22 & 15.6 \\
\hline Twitter & 38 & 27.0 \\
\hline Instagram & 44 & 31.2 \\
\hline YouTube & 26 & 18.4 \\
\hline Google & 10 & 7.1 \\
\hline Snapchat & 1 & 0.7 \\
\hline
\end{tabular}

\section{The Relationship between Social Media Addiction and Academic Performance}

Table 5 shows the result of Kruskal Wallis test to find the relationship between social media addiction and academic performance. The median $\pm I Q R$ for first class, second upper class and second lower class are $3.00 \pm 0.00$ respectively. The $\mathrm{z}$ statistics for academic performance is 0.373 and $p$ value is 0.830 , which is $p>0.05$. There is no significance difference between social media addiction and academic performance. Thus, there is no relationship between social media addiction and academic performance. 
Table 5: The Relationship between Social Media Addiction and Academic Performance

\begin{tabular}{|c|c|c|c|c|c|}
\hline \multirow{2}{*}{ Variable } & \multicolumn{3}{|c|}{ Median (IQR) } & \multirow{2}{*}{$\begin{array}{c}\mathrm{Z} \\
\text { statistic }\end{array}$} & \multirow{2}{*}{$\begin{array}{c}P \\
\text { value }\end{array}$} \\
\hline & \multicolumn{3}{|c|}{ Academic Performance } & & \\
\hline \multirow{2}{*}{$\begin{array}{l}\text { Level of } \\
\text { Addictiveness }\end{array}$} & First class & $\begin{array}{c}\text { Second upper } \\
\text { class }\end{array}$ & $\begin{array}{c}\text { Second lower } \\
\text { class }\end{array}$ & \multirow{2}{*}{0.373} & \multirow{2}{*}{0.830} \\
\hline & $3.00(0.00)$ & $3.00(0.00)$ & $3.00(0.00)$ & & \\
\hline
\end{tabular}

\section{DISCUSSION}

\section{Level of Social Media Addiction among Nursing Students}

From this study, majority of the students were being addicted by social media. To place the results in perspective, the mean for the social media addiction was mostly related with virtual communication with the mean score of 25.23 compared to study by Bilgin \& Ibrahim Tas (2018), who had 21.46 for social addiction of virtual communication. However, this result of the study was still in line with the study by Hawi \& Samaha (2016) which their mean score was 24.5 that indicate a moderate level of social media addiction where in range from 8 to 50 . Most of the previous study regarding social media addiction involves the sample of technical students (Koc \& Gulyagci, 2013), or students from Faculty of Education (Bilgin \& Tas, 2018) and coursework of mass communication (Al-Menayes, 2015). Rarely for the researchers to use nursing students as their samples. The occurrence of social media addiction appears to be differed with the study population.

\section{Platform That Nursing Students Most Exposed}

The findings of the study shown the list of social media platform that are most exposed by nursing student. Majority chose Instagram (31.2\%) as their platform and only $15.6 \%$ of respondent chose Facebook. Another study shown the contrast findings where Facebook become the highest platform with $80.2 \%$ while Instagram become the second least platform with only 3.16\% Malaysian exposed (Stat Counter, 2020). In line with that, $85 \%$ of undergraduates used Facebook as their social media sites and Instagram also become in the sixth place with $79.5 \%$ chose it as their platform (Olushola, 2018). However, our findings were supported by the NapoleonCat (2020) statistics with $30.2 \%$ and $22.1 \%$ users among the age of 18 to 24 -yearold who used Instagram and Facebook respectively which was parallel with nursing students' age in this study. Based on the findings, Snapchat recorded as the least exposed social media with only one respondent $(0.7 \%)$ chose that platform. This is supported by Fareez (2016) study which revealed that the method of adding friends on Snapchat is quite difficult compared to other application where Snapchat need a pro-active approach from the user to add friends which they need to share their Snapchat ID's to others first. However, study by Suwayri (2016) showed contrast result to our findings, where the participants were commonly addicted to Snapchat $(41.2 \%)$. In line with that, findings in the America recorded that $27 \%$ of American used Snapchat in 2018 (Smith \& Anderson, 2018). The findings were contradicting due to the location demographics of the findings. On the other hand, Member (2020) mentioned that there was lack of research in the usage of Snapchat in Malaysia. Thus, this may contribute to the reason why Snapchat has become the least exposed social media among students in Malaysia.

\section{Relationship between Social Media Addiction with Academic Performance of Nursing Students}

Justification on the findings in our current research show that excessive use of social media did not give a negative effect on their academic performance. This is because some students' performance remains the same even though they were addicted with social media platforms. The finding is consistent with findings of past studies by Othman, Fariha, \& Ngah (2017) that found that there was no significant relationship between social media usage and academic performance as the main factors that contribute to the poor academic performance was students' behaviour and poor time management. Another reason was that social media usage does influence students' but in a positive way. About 53.2\% of students agree that the usage of social media does helped them to improve their grades and half of the students still can perform well in academics even if they stop using social media. According to the outcome, majority of the respondents clearly indicated that social media can be used to discuss assignments, group discussion and also improve interaction between lecturers and classmate (Helou \& Rahim, 2014). Another study showed the lack of focus by college students itself have negative impact on academic grades (Mastrodicasa \& Metellus, 2013) which does not relate to social media.

\section{CONCLUSION}

This study has examined and measured the 
fundamental effect of use of social media addiction on academic success of students. The findings of this study showed that there is no significant relationship between social media addiction and academic performance. Undoubtedly, social media can cause addiction as in this study result in high level of addiction. At the same time, it also increases the productivity and academic performance of the students if they use it wisely. Utilizing social networks in a constructive manner will enable student and young people to develop information which will be utilized to improve their academic success. Hence, for upcoming studies it is essential to investigate the effect of social media use on some other possible factors including student goal, fulfilment to university regulations as well as attitude. Besides that, the correlation with several other variables will play an important role in evaluating the actual link among social media addiction and academic achievement, further research is needed to strongly reveal the fundamental frameworks in between two factors.

\section{Conflict of Interests}

The authors declare that there is no conflict of interests.

\section{ACKNOWLEDGEMENT}

The authors would like to thank the all participating students, lecturers, and faculty administrators involved.

\section{REFERENCES}

Abbas, J., Amman, J., Nurrunabi, M., \& Bano, S. (2019). The impact of social media on learning behavior for sustainable education: Evidence of students from selected universities in Pakistan. Sustainability, 11(6), 1683.

Al-Menayes, J. (2015). Dimensions of social media addiction among university students in Kuwait. Psychology and Behavioral Sciences, 4(1), 23.

Bilgin, O., \& Taş, İ. (2018). Effects of perceived social support and psychological resilience on social media addiction among university students. Universal Journal of Educational Research, 6(4), 751-758.

Cengiz, Ş. (2018). Social Media Addiction Scale - Student Form: The Reliability and Validity Study. The Turkish Online Journal of Educational Technology, 17(1),169-182.

Fareez, S. (2016). Marketing Magazine Asia. Retrieved from: https://marketing magazine.com.my/5-insights-onmalaysian-snapchat-users.

Giunchiglia, F., Zeni, M., Gobbi, E., Bignotti, E., \& Bison, I. (2018). Mobile social media usage and academic performance. Computers in Human Behavior, 82, 177-185.

Hawi, N. S., \& Samaha, M. (2017). The relations among social media addiction, self-esteem, and life satisfaction in university students, Social Science Computer Review, 35(5), 576-586.

Helou,A. M., \& Rahim, N. Z.A. (2014). The influence of social networking sites on students' academic performance in Malaysia. International Journal of Electronic Commerce Studies, 5(2), 247-254.

Koc, M., \& Gulyagci, S. (2013). Facebook addiction among Turkish college students: the role of psychological health, demographic, and usage characteristics. Cyberpsychology, Behavior and Social Networking, 16(4), 279-284.

Lamia A. A., Osman, Z.H.H., \& Farrag, E.A. (2018). Internet Addiction and Related Risk Factors Among Faculty of Nursing Student At El Fayuom And Dammam University. The Malaysian Journal of Nursing (MJN), 9(4), 95-105.

Mastrodicasa, J., \& Metellus, P. (2013). The impact of social media on college students. Journal of College and Character, 14(1), 21-30.

Member, S. (2020). Snapchat use among Malaysian Undergraduates in Public and Private Universities. Retrieved from: https://www.monash.edu.my/mdp/ga21/research/projects/snapchat-use-among-malaysian-undegraduatesin-public-and-private-universities.

Mukhtar, S., Ali, A., Muqeet, A., Hussain, M., Afzal, M., \& Gilani, S.A. (2018). Influence of Social Media on Nursing 
Student's Academic Performance. Independent Journal of Allied Health Sciences, 3(1), 183-189.

NapoleonCat. (2020). Social Media Users in Malaysia. Retrieved from: https://napoleoncat.com/stats/social-mediausers-in-malaysia .

Olushola, I. (2018). Social Media Usage and Impact on the Academic Learning and Performance of Undergraduate Students. Retrieved from: https://www.academia.edu/41646257/social_media_usage_and_impact_ on_the_academic_learning_and_performance_of_undergratuate_students

Osharive, P. (2015). Social Media and academic performance in. Unpublished.

Othman, W. R., Fariha, Z., \& Ngah, N. H. (2017). Impact of Social Media Usage on Students Academic Performance in Terengganu, Malaysia. Journal of Applied Environmental and Biological Sciences, 7(5), 142-143.

Oueder, M., \& Abousaber, I. (2018). A Study on the Impact of social Media Usage on Student Academic Performance," University of Tabuk an Example. American Scientific Research Journal for Engineering, Technology, and Sciences (ASRJETS), 40(1), 77-88.

Siddiqui, S., \& Singh, T. (2016). Social media its impact with positive and negative aspects. International Journal of Computer Applications Technology And Research, 5(2), 71-75.

Smith, A., \& Anderson, M. (2018). Social Media use 2018: Demographics and Statistics. Retrieved from: https://www.pewresearch.org/internet/2018/03/01/social-media-use-in-2018/

StatCounter. (2019). Social Media Stats Malaysia. Retrieved from: https://gs.statcounter.com/social-mediastats/all/malaysia

Suwayri, S. M. (2016). The impact of social media volume and addiction on medical student sleep quality and academic performance: A cross-sectional observational study. Imam Journal of Applied Science, 1(2), 4103. 